Journal of Sustainable Agricultural Sciences
http://jsas.journals.ekb.eg/

أثر منظومة التحول الرقمي للاعم الغذائي علي بعض مؤشرات الدعم الغذائي

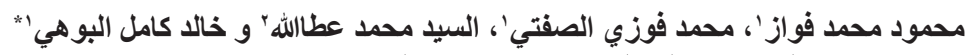

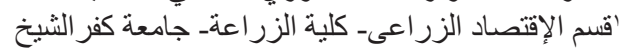

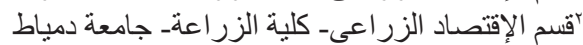

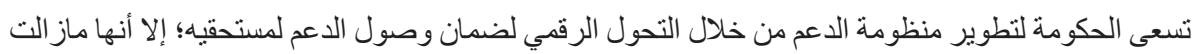

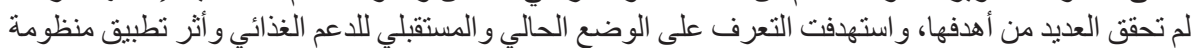

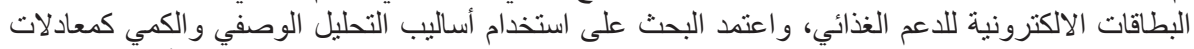

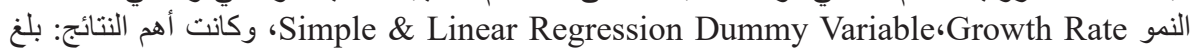

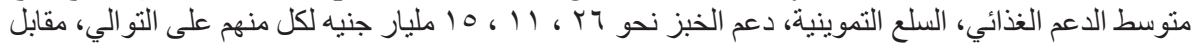

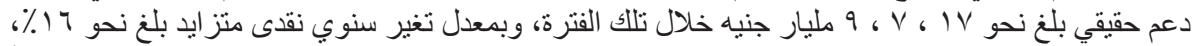

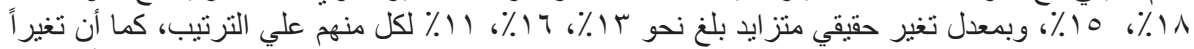

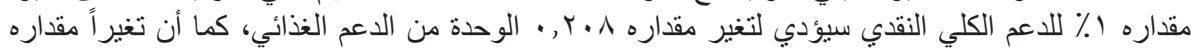

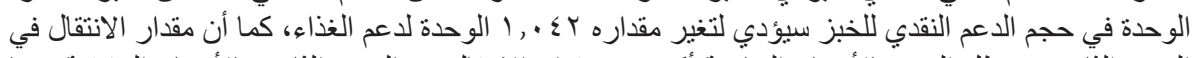

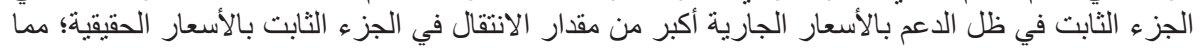

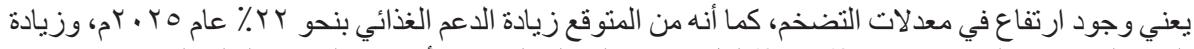

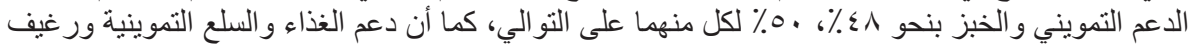

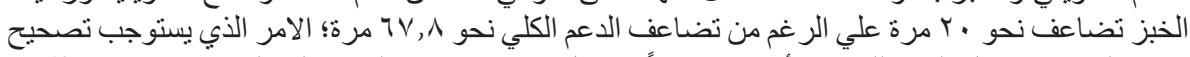

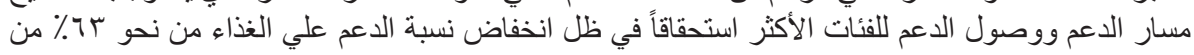
الدعم الكلي لنحو 9 \%٪ من الدعم الكلي خلال فترة البحث.

الكلمات الافتتاحية: التحول الرقمي، الدعم الغذائي، دعم الخبز ، البطاقات الالكترونية، الدعم التموينى، الدتغيرات

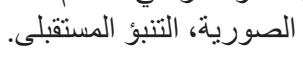

توفير الاحتياجات الغذائية للسكان، مما دفع الدولة لمواجه ذلك الكاج

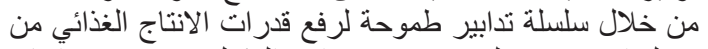

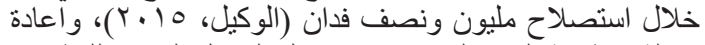

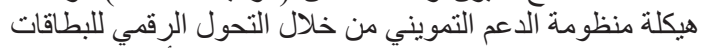

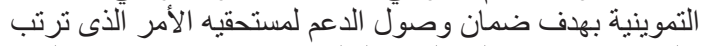

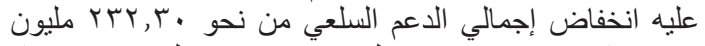

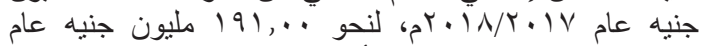

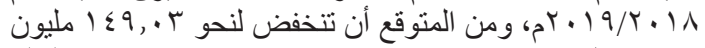

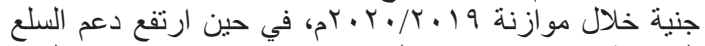

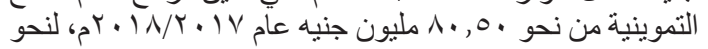

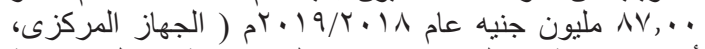

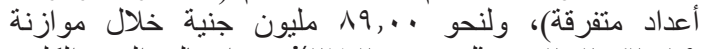

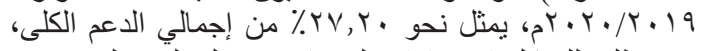

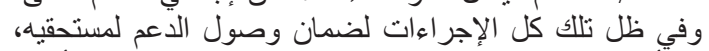

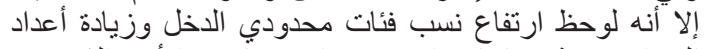

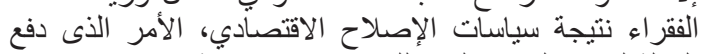

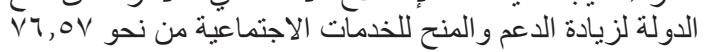

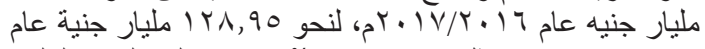

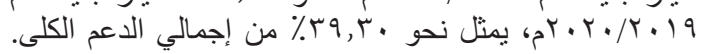

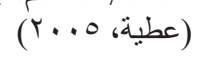

مقدمة

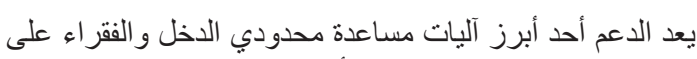

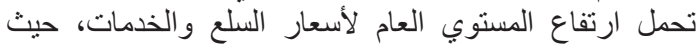

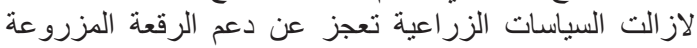

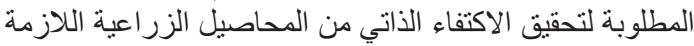

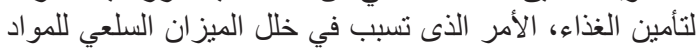

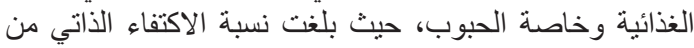

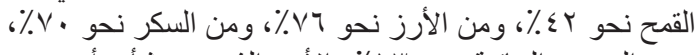

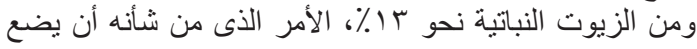

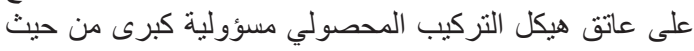
المنافسة علي الموارد المحدودة و المتاحة بهدف تحفيق التئي الاهداف العامة للاولة. - ملي.

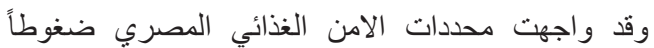

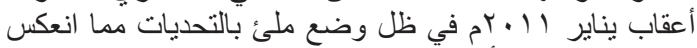

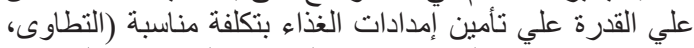

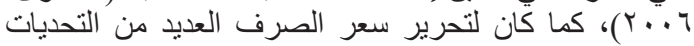

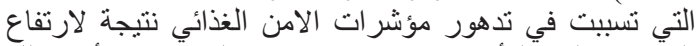

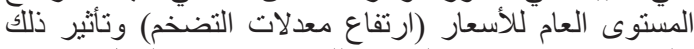
على معدلات الانفاق الغذائي للفئات محدودة اللفات الدخل، وكيفية 
يتضح من بيانات جدول ( (1) أن مثتوسط الدعم النقدي في مصر

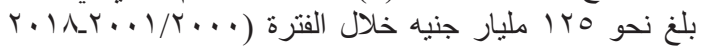

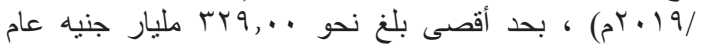

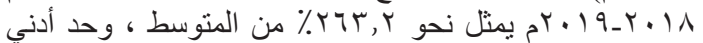

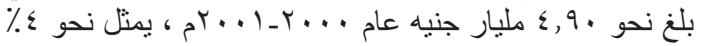

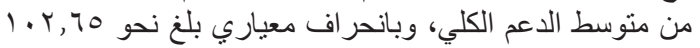

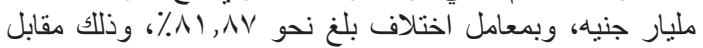

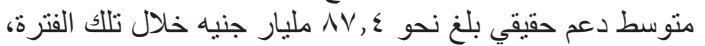

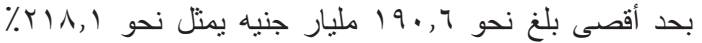

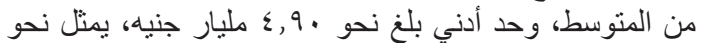

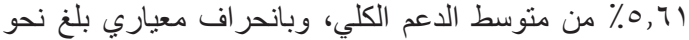

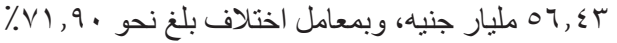

وبتقدير معادلة الاتجاه الزمني العام لتطور الدعم الكلي في

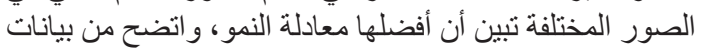

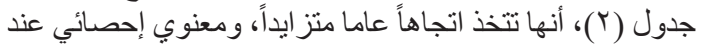

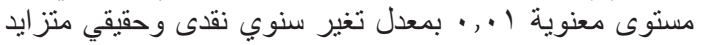

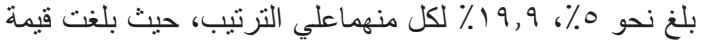

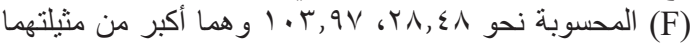

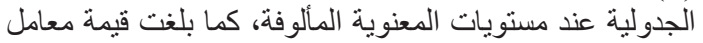

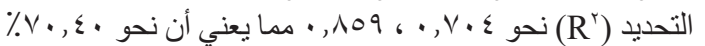

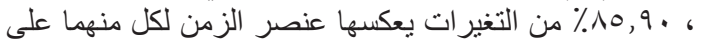

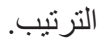

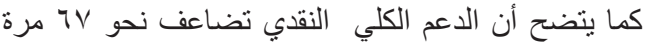

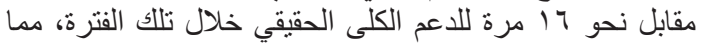
يعنى ارتفاع معدلات التضخم و النمو السكاني.

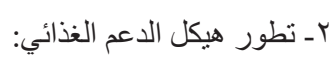

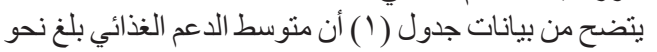

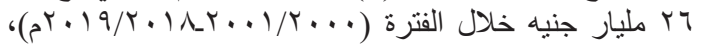

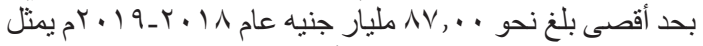

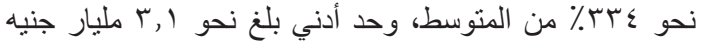

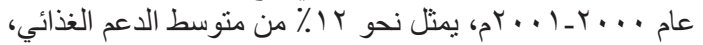

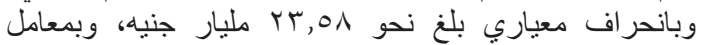
اختلاف بلغ نحو 00, • 9 ٪، وذللك مقابل متوسط دعم حقيقي بلغ

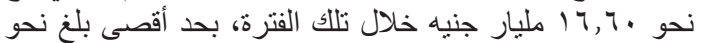

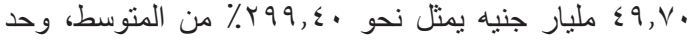

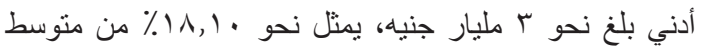

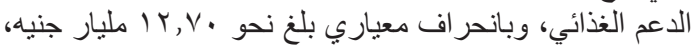

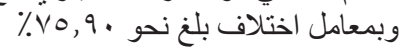

وبتقدير معادلة الاتجاه الزمني العام لتطور الدعم الغذائي في

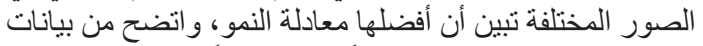

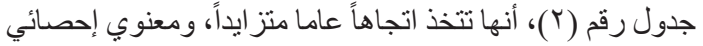

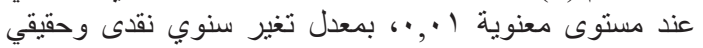

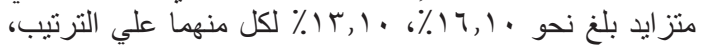

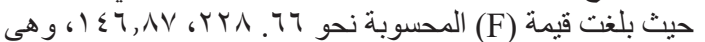

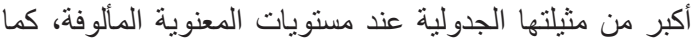

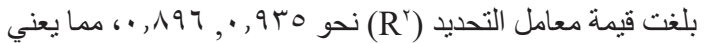

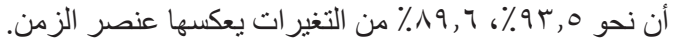

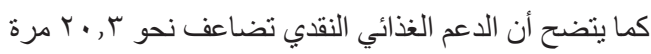

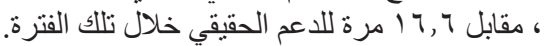

مشكلة البحث

علي الرغم من الجهود المبذولة من جانب و اضعي السياسات

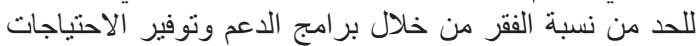

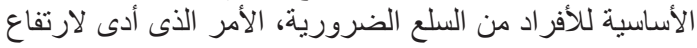

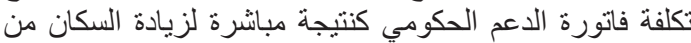

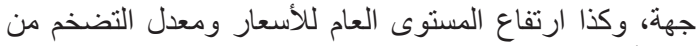

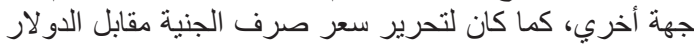

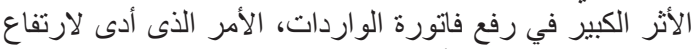

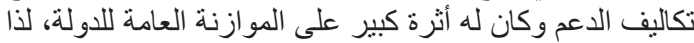

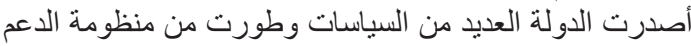

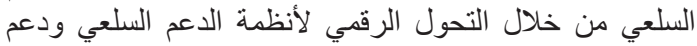

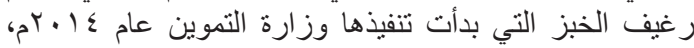

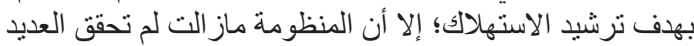

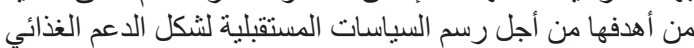

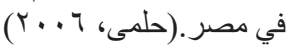

أهداف البحث

استهدفت الدراسة التعرف على الوضع الحالي لهيكل وبنود

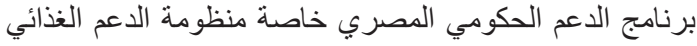

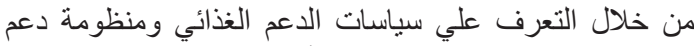

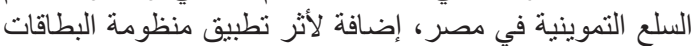

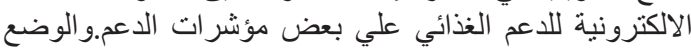
المستقبلي لهيكل وبنود الدعم للاني

والكمي حيث تم استخدام الأراسة على استخدام أساليب التحليل الوصفي

1 ـ معادلات الانحدار البسيط في الصورة الآسية لتقدير معدلات

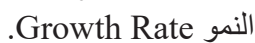

Y Simple \& Linear معادلات الانحدار البسط و المتعدد Regression

Backward Regression

مـ المتغير ات الصورية Dummy Variable

ع- - التنبؤ المستقبلي باستخدام نماذج التنبؤ الأسى Exponential ModelExponential ModelSingle and Double-

مصادر البيانات

كما اعتمدت الدراسة في تحقيق أهدافها على بيانات ثانوية

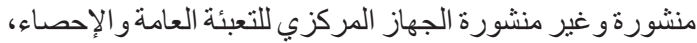

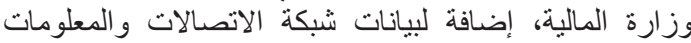
الدولية 》الإنترنتش) الدالية.

النتائج البحثية

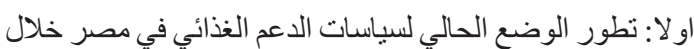

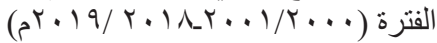

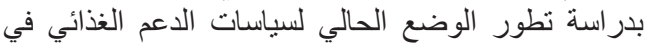
مصرمن خلال التعرف على تطور هيكل الدعم الكلي والغذائي لئي

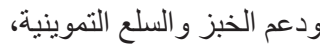
ا ـ تطور هيكل الدعم الكلى: - ملى 


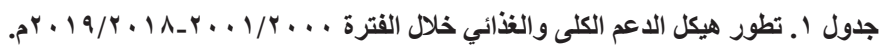

\begin{tabular}{|c|c|c|c|c|c|c|c|c|}
\hline معامل الاختلاف؛ & الاححراف|لمعياري & لسنة & الحدالأقصى & ل لسنة & الحد الأنىى & $\begin{array}{c}\text { (مليارجنية) } \\
\text { (لمتوسط }\end{array}$ & \multicolumn{2}{|c|}{ لمتغير } \\
\hline$\Lambda), A v$ & $1 \cdot r, 7$. & $r \cdot 11$ & rrq,. & $r \ldots$ & $0, \ldots$ & rro,. & جاري & \\
\hline v1, q. & $07, \varepsilon T$ & $r .1 \Lambda$ & $19 \cdot, 7$ & r... & $\varepsilon, q$. & $V \Lambda, \varepsilon$ & حقيقي & \\
\hline $9 ., 00$ & $r T, O \Lambda$ & $r \cdot 11$ & $\Delta v$, & $r \ldots$ & $r, .$. & ru, & جاري & \\
\hline$v_{0}, q$. & $\mid r, v$. & r.1A & $\varepsilon 9, v$ & r... & $r, 1$. & 17,7 & حقيقي & \\
\hline$V v, \wedge q$ & 11,10 & $r .1 \Lambda$ & $\leqslant 7,$. & r... & $r, \ldots$ & $10,$. & جاري & \\
\hline$T \varepsilon, .$. & $7, r$. & $r .1 \Lambda$ & r.,. & r... & 1,9 . & $\Lambda, q$ & حقيقي & \\
\hline $11 \cdot, 9 \leq$ & $K, \ldots$ & $r .11$ & $\varepsilon r, \ldots$ & $r \ldots$ & $1, \ldots$ & $1 \cdot, \lambda$. & جاري & الدع ل الدع \\
\hline $99, \ldots$ & 7,70 & $r .1 \Lambda$ & $r r, v$ & r... & $1, Y$. & $7, V Y$ & حقيقى & التمويني \\
\hline
\end{tabular}

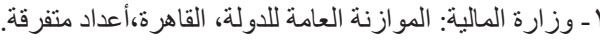

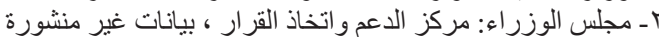

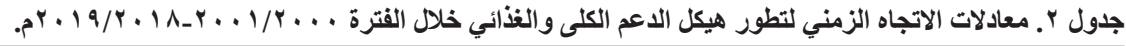

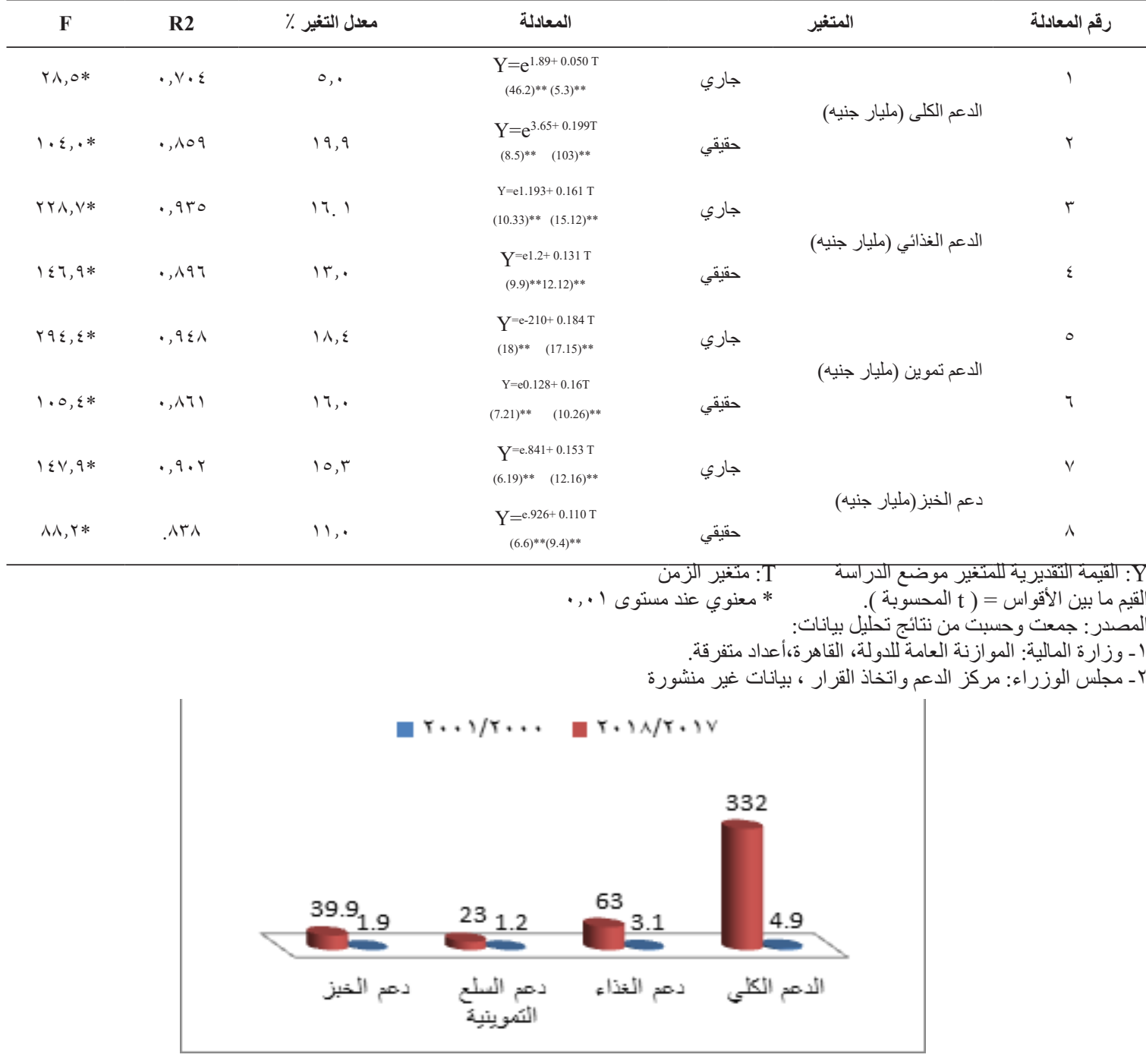

شكل 1. تطور مقررات الاعم بالمليار جنيه المصدر : جمعت وحسبت من بيانات وز ارة المالية: المو ازنة العامة للدولة، القاهرة، أعداد متفرقة

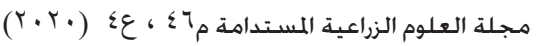


وبتقدير معادلة الاتجاه الزمني العام لتطور دعم الخبز في

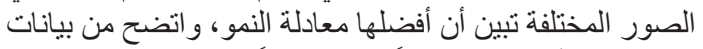

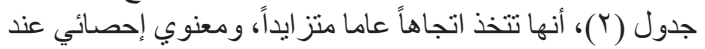

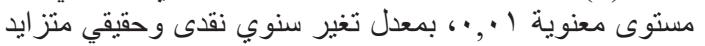

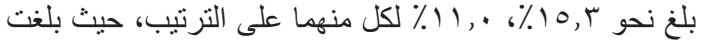

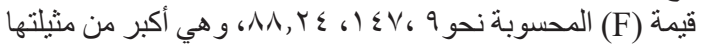

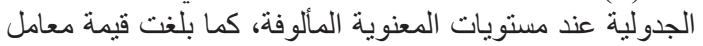

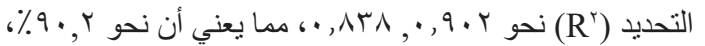

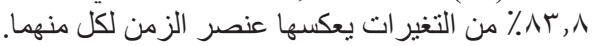

ويوضح شكل رقم (r) تطور الدعم الغذائي و السلع التموينية ورغيف الخبز خلال فترة الدر اسة

ومما سبق بتضح أن دعم الغذاء ودعم السلع التموينية ودعم

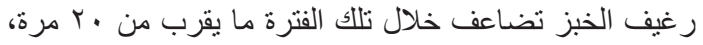

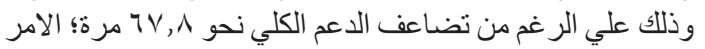

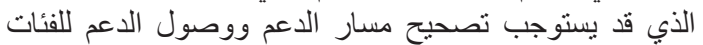

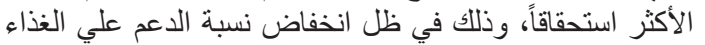

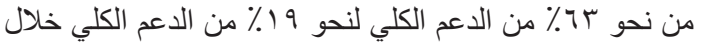
فترة الدر اسة. ثانياً: العلاقة بين الدعم الكلي و الدعم الغذائي

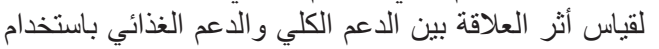

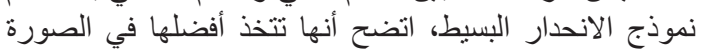
الخطية، حيث تتخذ الثكل التالي باستخدام الأسعار الجارية: $\mathrm{Y}=0.039+0.208 \mathrm{X}$

(0.10) $(8.80)^{* *}$

$\mathrm{R}=0.906 \quad \mathrm{R}^{2}=0.820 \quad \mathrm{R}^{-2}=0.809 \quad \mathrm{~F}=77.49 *$

كما تتخذ الثكل التالي باستخدام الأسعار الحقيقية:

$\mathrm{Y}=1.118+0.197 \mathrm{X}$

(0.43) $(7.36)^{* *}$

$\mathrm{R}=0.872 \quad \mathrm{R}^{2}=0.761 \quad \mathrm{R}^{-2}=0.747 \quad \mathrm{~F}=54.16^{*}$ r- تطور هيكل دعم السلع التموينية:

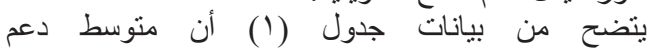

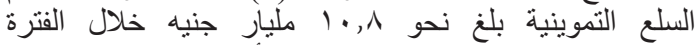

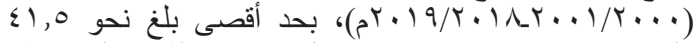

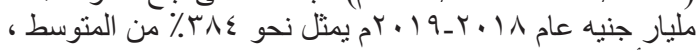

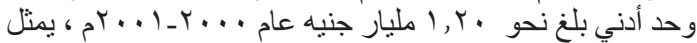

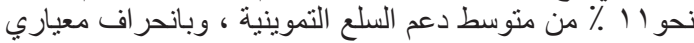

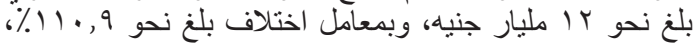

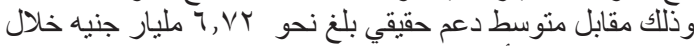

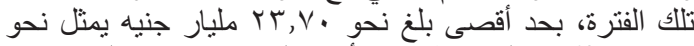

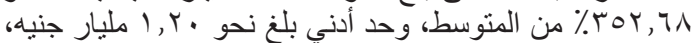

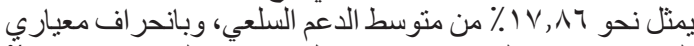

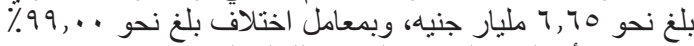

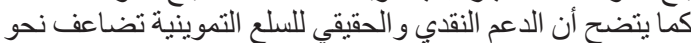
r 19 19 مرة، مقابل نحو خلاّل تلأك الفترة.

وبتقدير معادلة الاتجاه الزمني العام لتطور دعم السلع

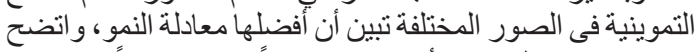

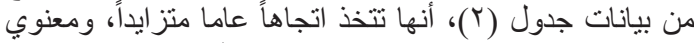

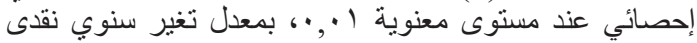

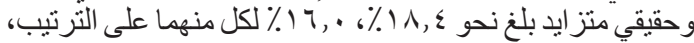

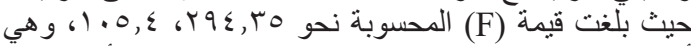

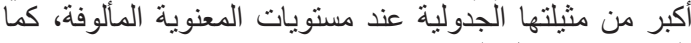

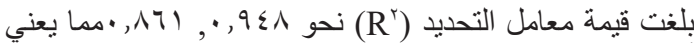

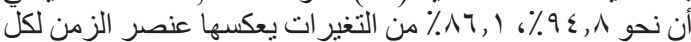

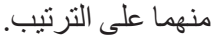

ع - تطور هيكل دعم الخبز:

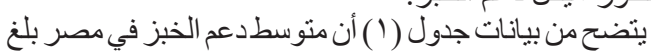

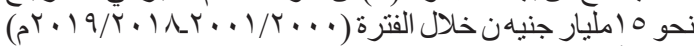

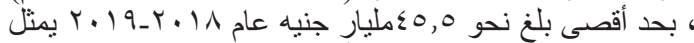

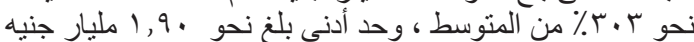

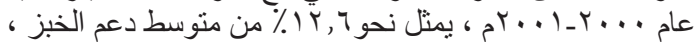

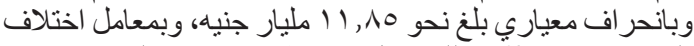

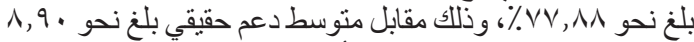

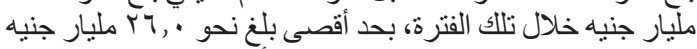

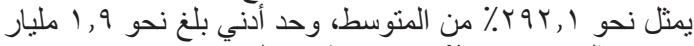

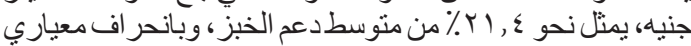

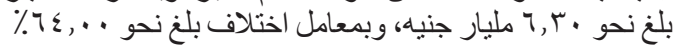

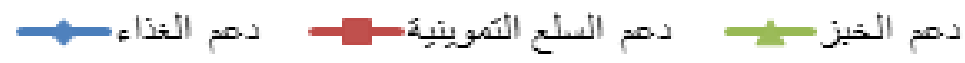

63

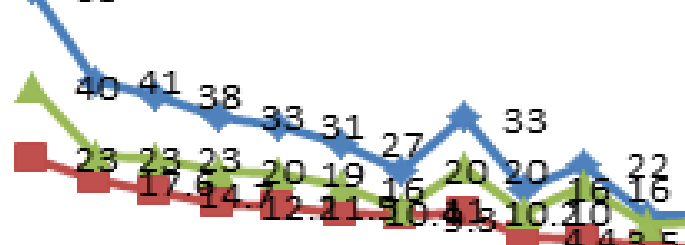

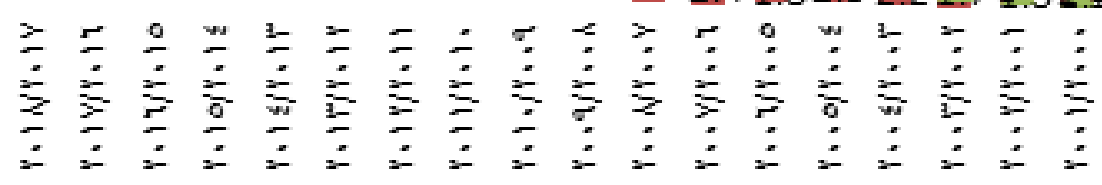

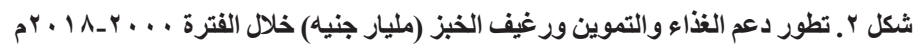

المصدر : جمعت وحسبت من بياناتوز ارة المالية: الموازنة العامة للدولة، القاهرة،أعداد متفرقة

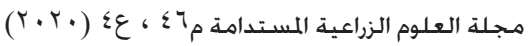


$\mathrm{Y}=0.32+1.042 \mathrm{X}_{1}+0.001 \mathrm{X}_{2}+0.003 \mathrm{X}_{3}$

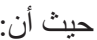

(0.6) $(8.23)^{* *}(2.62)^{* *}(6.96)^{* *}$

$\mathrm{R}=0.998 \quad \mathrm{R}^{2}=0.996 \quad \mathrm{R}^{-2}=0.995 \quad \mathrm{~F}=1203$

في ظل الأسعار الحقيقية، تتخذ الثكل التالي:

$\mathrm{Y}=0.087+1.027 \mathrm{X}_{1}+0.001 \mathrm{X}_{2}+0.003 \mathrm{X}_{3}$

$(0.14)(8.56)^{* *}(2.88)^{* *}(6.35)^{* *}$

$\mathrm{R}=0.997 \quad \mathrm{R}^{2}=0.994 \quad \mathrm{R}^{-2}=0.992 \quad \mathrm{~F}=584.71$

ويتضح من المعادلتان المقدرتان أنهما معنويتان إحصائياً عند

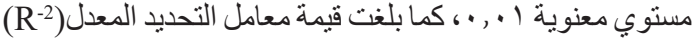

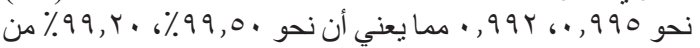

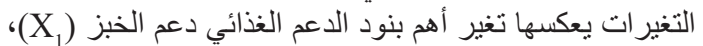

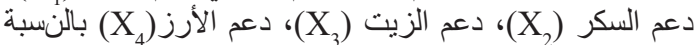

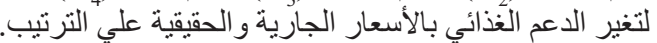
كما يتضح من المعادلتان المقدرنان أن:

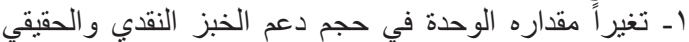

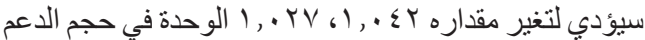
الغذائي لكل منهما علي الترتيب.

r- تغيراً مقداره الوحدة في حجم دعم السكر النقدي والحقبقي سيؤدي لتغير مقداره ا ل . ., . . الوحدة في حجم الدعم الغذائي كل منهما علي الترتيب.

rـ تغيراً مقداره الوحدة في حجم دعم السكر النقدي والحقيقي سيؤدي لتغير مقداره ب +.., • الوحدة في حجم الدعم الغذائي

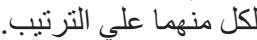

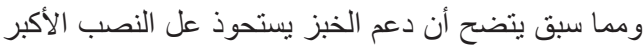

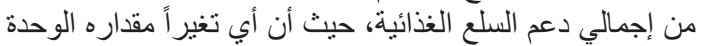

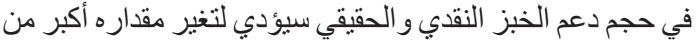

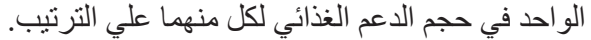
ثالثاً: أثر تطبيق منظومة البطاقات الالكترونية للاعم الغذائي علي لئي

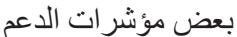

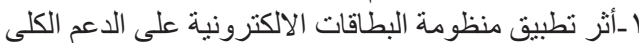

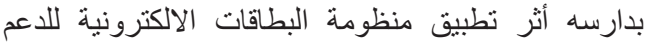

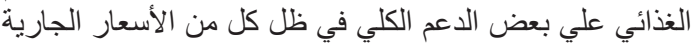
و الحقيقية، يتضح من بيانات جدول (T) ما يلي:

في ظل الدعم بالأسعار الجارية:

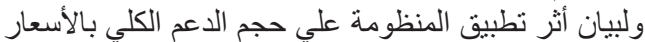

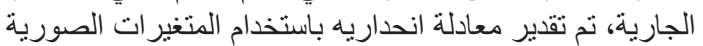

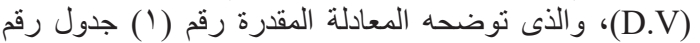

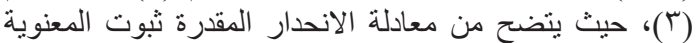

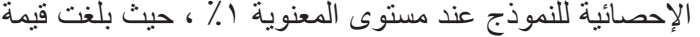

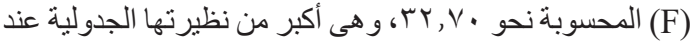

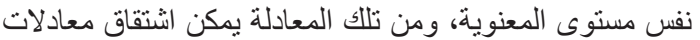
توضح أثر تطبيق المنظومة التالية:-

$\mathrm{Y} 0=66$

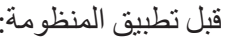

$\mathrm{Y} 1=240$

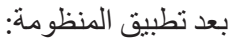

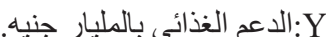

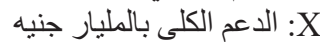

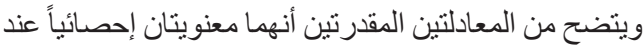

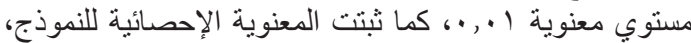

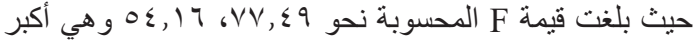

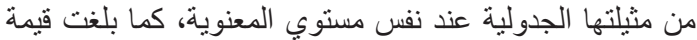

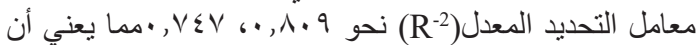

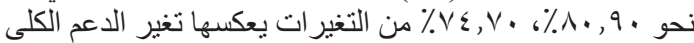
بالنسبة لتغير الاعم الغذائي في ظل مل الدعم الكلي بالأسعار الجارية

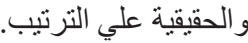

كما يتضح من المعادلتان المقدرتان أن تغيراً مقداره الوحدة

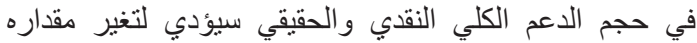

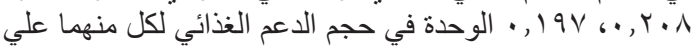

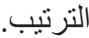

ولبيان أثر العلاقة بين حجم الدعم الغذائي (Y)، و وأهم بنود

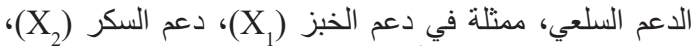

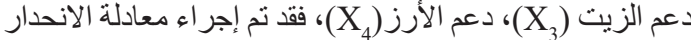

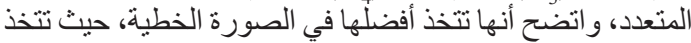
الشكل التالي باستخدام الأسعار الجارية:

$0 . \mathrm{Y}=0.67+1.041 \mathrm{X}_{1}+0.001 \mathrm{X}_{2}+0.001 \mathrm{X}_{3}+0.003 \mathrm{X}_{4}$ $(0.6)(8.23)^{*}(0.74)(2.1)^{* *(6.89) *}$

$\mathrm{R}=0.998 \quad \mathrm{R}^{2}=0.996 \quad \mathrm{R}^{-2}=0.996 \quad \mathrm{~F}=874.7 *$

كما تتخذ الشكل التالي باستخدام الأسعار الحقيقية: $\mathrm{Y}=0.111+1.023 \mathrm{X}_{1}+001 \mathrm{X}_{2}+0.001 \mathrm{X}_{3}+003 \mathrm{X}_{4}$ $(0.12)(8.27) *(0.39)(1.9) * *(4.87) *$

$\mathrm{R}=0.997 \quad \mathrm{R}^{2}=0.994 \quad \mathrm{R}^{-2}=0.993 \quad \mathrm{~F}=826$

$$
\begin{aligned}
& \text { حيث أن: } \\
& \text { الدعم الغذائي بالمليار جنيه. }
\end{aligned}
$$

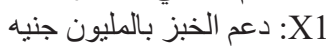

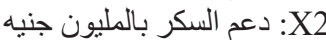

$$
\begin{aligned}
& \text { X3 دعم الزيوت بالمليون جنيه :X2 دعيه } \\
& \text { X4 دعم الأرز بالمليون جنيه بالطيون جنيه }
\end{aligned}
$$

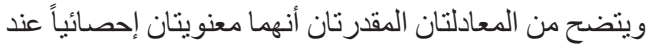

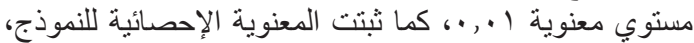

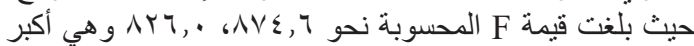

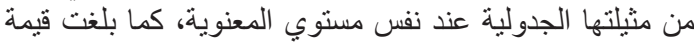

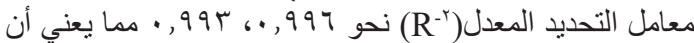

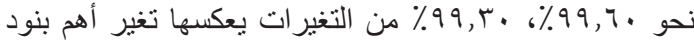

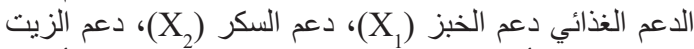

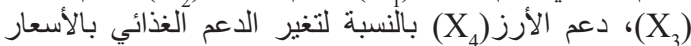
الجارية و الحقيقية علي الترتيب.

ولبيان أهم بنود الدعم الغذائي تأثيراً علي الدعم الغذائي، فقد

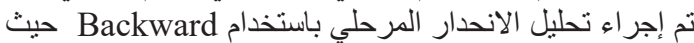

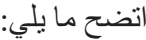
في ظل الأسعار الجارية، تتخذ الثكل التالي:

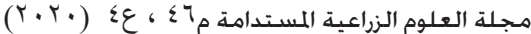


في ظل الدعم بالأسعار الجارية: ولبيان أثر تطبيق المنظومة علي الإني حجم الدعم الغذائي بالأسعار

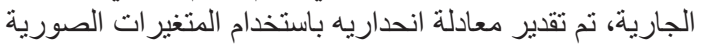
(D.V)

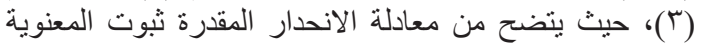

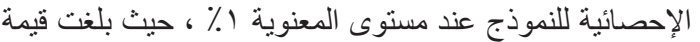

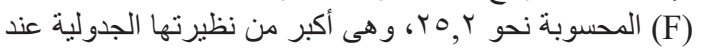

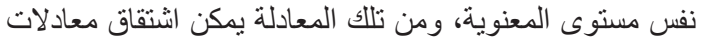
توضح أثر تطبيق المنظومة التالية:-

$\mathrm{Y} 0=13.4$

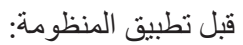

$\mathrm{Y} 1=30.8$ بعد تطبيق المنظومة:

ويتضح من المعادلة المقدرة ارتفاع حجم الاعم بالأسعار

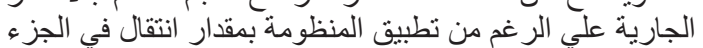

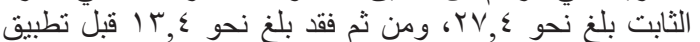

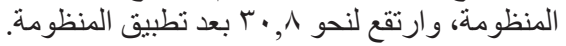

في ظل الدعم بالأسعار الحقيقية: ولبيان أثر تطبيق المنظومة الأنة علي حجم الدعم الغذائي بالأسعار

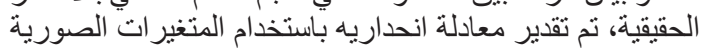

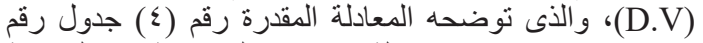

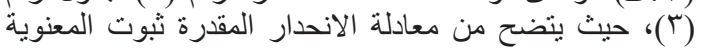

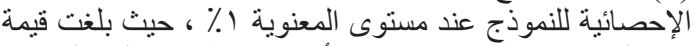

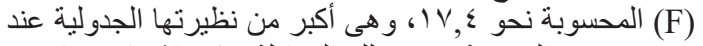
نفس مستوى المعنوية، ومن تلك المعادية المعادلة يمكن اشتقاق معادلات توضح أثر تطبيق المنظومة التالية:-
$\mathrm{Y} 0=10$

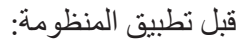
$\mathrm{Y} 1=23.40$

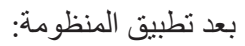

ويتضح من المعادلة المقدرة ارتفاع حجم الاعم بالأسعار

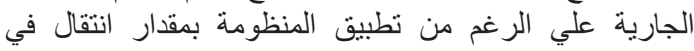

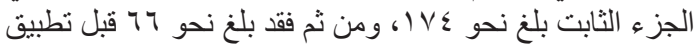

المنظومة، وارتقع لنحو • ؟ ب بعد تطبيق المنظومة.

في ظل الدعم بالأسعار الحقيقية:

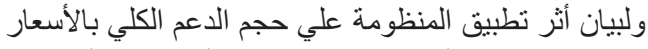

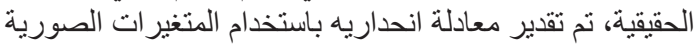
(Y.V)

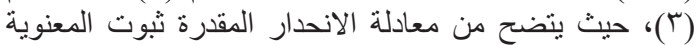

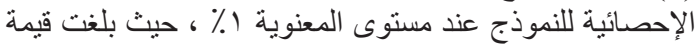

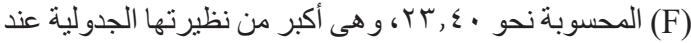

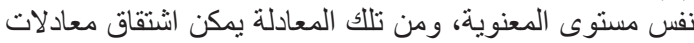
توضح أثز تطبيق المنظومة التالية:-

Y0 = 47.50

$\mathrm{Y} 1=137.50$

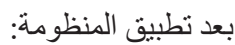

ويتضح من المعادلة المقدرة ارتفاع حجم الاعم بالأسعار

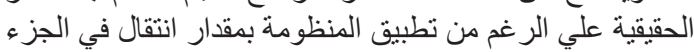

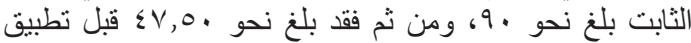

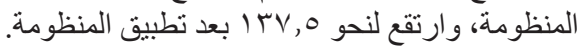

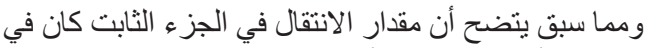

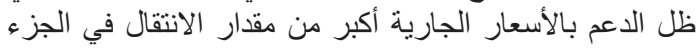

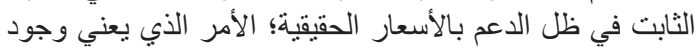

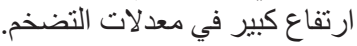

r أثثر تطبيق منظومة البطاقات الالكترونية علي الدعم الغذائي

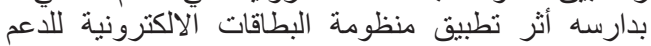

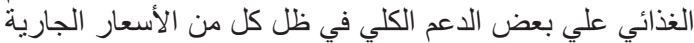

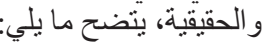

جدول ؟ـ أثر تطبيق منظومة البطاقات الاككترونية للاعم الغذائي علي أهم بنود الاعم الكلي.

\begin{tabular}{|c|c|c|c|c|c|c|c|c|c|c|c|c|}
\hline \multicolumn{6}{|c|}{ في ظل القيم بالأسعار الحقيقية } & \multicolumn{5}{|c|}{ في ظل القيم بالأسعار النقدية (الجارية) } & \multirow{3}{*}{ المتغير } & \multirow{3}{*}{ م } \\
\hline \multicolumn{2}{|c|}{ أثر المنظومة } & \multirow{2}{*}{$\mathbf{F}$} & \multirow{2}{*}{$\mathbf{R}^{2}$} & \multirow{2}{*}{ المعادلة } & \multirow{2}{*}{ e } & \multicolumn{2}{|c|}{ 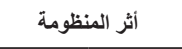 } & \multirow{2}{*}{$\mathbf{F}$} & \multirow{2}{*}{$\mathbf{R}^{2}$} & \multirow{2}{*}{ المعادلة } & & \\
\hline بعد & قبل & & & & & بعد & قبل & & & & & \\
\hline $1 T V, 0$ & $\varepsilon v, 0$ & 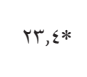 & $\cdot, 09$ & $\begin{array}{r}Y=47,5+90^{4 d} \\
(4.8)^{* * *} \quad(4.8)^{* *}\end{array}$ & $r$ & $r \leq$. & 77 & $r T, V *$ & $\cdot, \mathrm{TV}$ & $\begin{array}{l}Y=66+174 d \\
(4.1)^{* *} \quad(5.7)^{* *}\end{array}$ & جنيه) الدعم الكلى (مليار & 1 \\
\hline$r r,$. & 1. & $\mid V, \leq *$ & $\cdot$, Or & $\begin{array}{r}Y=10+13,^{, 4 d} \\
(5.9)^{* * *}(4,2)^{* * *}\end{array}$ & $\varepsilon$ & $\varepsilon \cdot, \lambda$ & $1 \%, \varepsilon$ & ro, r* & $\cdot, 7)$ & $\begin{array}{l}\mathrm{Y}=13,4+27,4 \mathrm{~d} \\
(4.7)^{* *} \quad(5)^{* *}\end{array}$ & 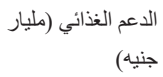 & $r$ \\
\hline $1 \leqslant, 7$ & 7,1 & $1 \pi, 7 * *$ & $\cdot, \leq 7$ & $\begin{array}{r}\mathrm{Y}=6,8+7,8 \mathrm{~d} \\
(6)^{* *} \quad(3.7)^{* * *}\end{array}$ & 7 & $r_{0, \varepsilon}$ & 9 & $r 1, \varepsilon *$ & , OV & $\begin{array}{l}Y=9+16,^{, 4 d} \\
(4.8)^{* * *}(4.6)^{* *}\end{array}$ & مليار جنيه) (عم الخبز & 0 \\
\hline rot. & ११६ & $\mathbb{1},\{* *$ & $\cdot, \leq 0$ & $\begin{array}{r}\mathrm{Y}=994+1660^{\mathrm{d}} \\
(4.1)^{* * *}(3.6)^{* * *}\end{array}$ & $\wedge$ & דצד & 1ros & $I V, Y *$ & , or & $\begin{array}{r}\mathrm{Y}=1354+3^{282 \mathrm{~d}} \\
(3.2)^{* * *}(4.1)^{* * *}\end{array}$ & مليون جنبه) ( دعم السكر & V \\
\hline$\leqslant 1 M$ & 10.1 & $1 \gamma, 9 *$ & ., or & $\begin{array}{r}Y=1501+2687^{\mathrm{d}} \\
(4.5)^{* * *}(4.2)^{* *}\end{array}$ & 1. & Vरq & r.OS & $\pi, \cdot *$ & $\cdot, 09$ & $\begin{array}{l}\mathrm{Y}=2054+5^{240 \mathrm{~d}} \\
(3.6)^{* * *} \quad(4.8)^{* *}\end{array}$ & دمث الزيوت & 9 \\
\hline ETK & 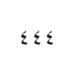 & rV,o* & $\cdot, v \cdot$ & $\begin{array}{l}\mathrm{Y}=444+884 \mathrm{~d} \\
(5.8)^{* * *} \quad(6.1)^{* * *}\end{array}$ & Ir & PTlo & TוT & $01,7 *$ & $\cdot, V 7$ & $\begin{array}{l}\mathrm{Y}=612+1703 \mathrm{~d} \\
(4.9)^{* * *}(7.1)^{* *}\end{array}$ & مليون جنيه) (لأرز & 11 \\
\hline 9rग & гqтq & r৭,०* & $\cdot, 70$ & $\begin{aligned} Y=2939 & +6272 d \\
& (4.8)^{* *}(5,4)^{* *}\end{aligned}$ & $1 \leqslant$ & $17 . \leq 47$ & $\varepsilon \cdot r$. & $r \tau, V *$ & $\cdot, v \cdot$ & $\begin{array}{l}\mathrm{Y}=4020+12026 \mathrm{~d} \\
(3.8)^{* * *}(6)^{* *}\end{array}$ & 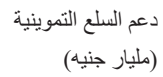 & 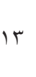 \\
\hline
\end{tabular}

D متغير صوري يأخذ القيمة (· ) قبل تطبيق المنظومة، والقيمة ( ( ) بعد تطبيق المنظومة. 
ع ـأثر تطبيق منظومة البطاقات الالكترونية علي الاعم الخبز

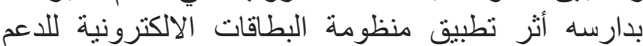
الغذائي علي بعض دُ دعم الخبز في ظل كل من من الأسعار الجارية

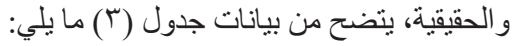
في ظل الدعم بالأسعار الجارية:

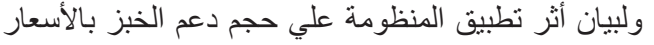

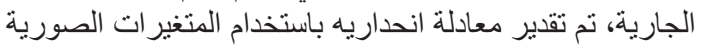
(P.V)

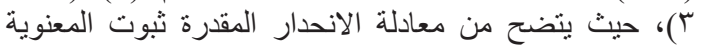

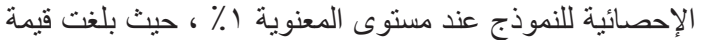

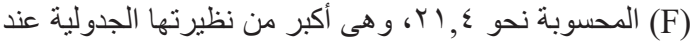

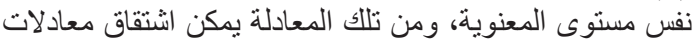
توضح أثر تطبيق المنظومة النالية:-

$\mathrm{Y} 0=9$

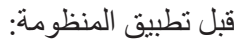

$\mathrm{Y} 1=25.4$

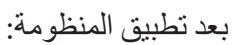
ويتضح من المعادلة المقدرة ارتفاع حجم الدعم بالأسعار

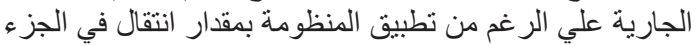

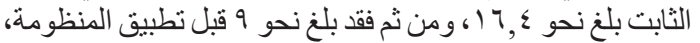

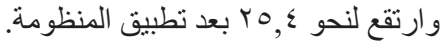

في ظل الدعم بالأسعار الحقيقية: ولبيان أثز تطبيق المنظومة علارئمة علي حجم دعم الخبز بالأسعار

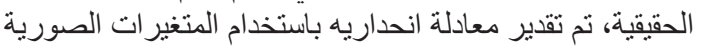
(P.V)

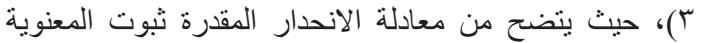

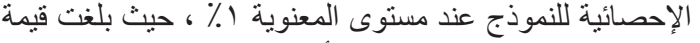

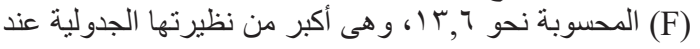

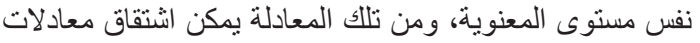
توضح أثر تطبيق المنظومة النالية:-

$\mathrm{Y} 0=6.8$

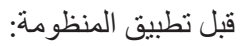

$\mathrm{Y} 1=14.60$

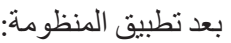

ويتضح من المعادلة المقدرة ارتفاع حجم الدعم بالأسعار

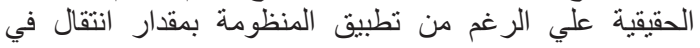

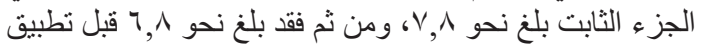

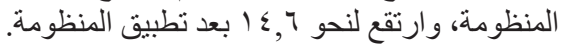

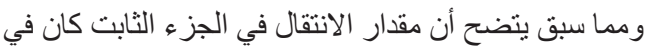

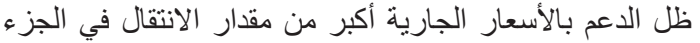

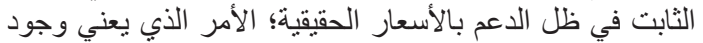

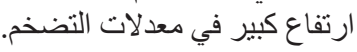

هـأثر تطبيق منظومة البطاقات الالكترونية علي الدعم السكر

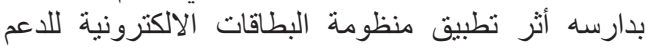

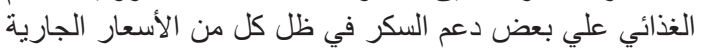

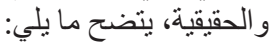
في ظل الدعم بالأسعار الجارية:

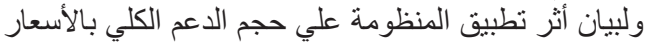

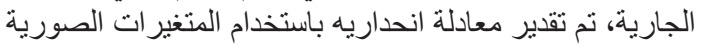

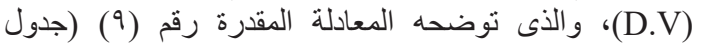

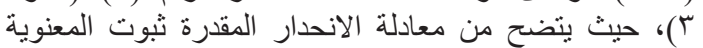

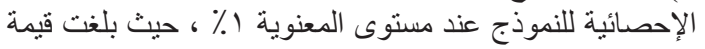

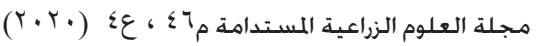

ويتضح من المعادلة المقدرة ارتفاع حجم الاعم بالأسعار

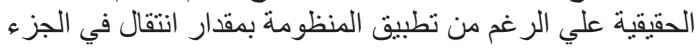

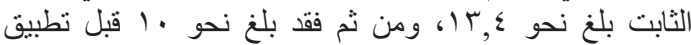

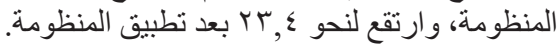

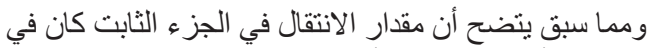

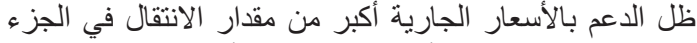
الثابت في ظل الدعم بالأسعار الحقيقية؛ الأمر الذي يعني الأني في وجود ارتفاع كبير في معدلات التضخم.

rـ أثر تطبيق منظومة البطاقات الاكترونية علي دعم السلع

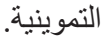
بدارسه أثر تطبيق منظومة البطاقات الالكترونية للاعم الغذائي علي بعض دعم السلع التموينية في ظل كل كل من الأسعار الجارية و الحقيقية، يتضح ما يلي: في ظل الدعم بالأسعار الجارية:

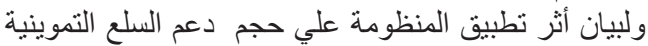

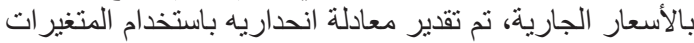

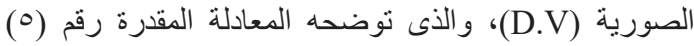

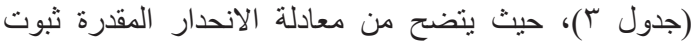

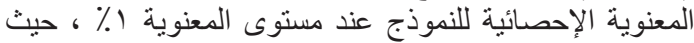

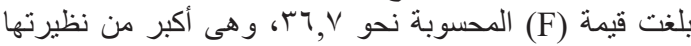

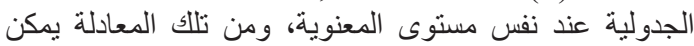
اشتقاق معادلات توضح أثر نطبيق المنظومة التالية:-

$\mathrm{Y} 0=4020$

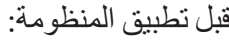

$\mathrm{Y} 1=16046$

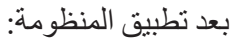

ويتضح من المعادلة المقدرة ارتفاع حجم الدعم بالأسعار

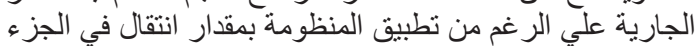

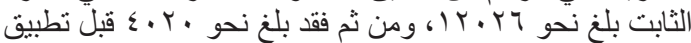

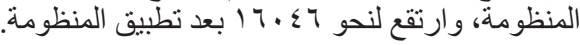

في ظل الدعم بالأسعار الحقيقية: ولبيان أثر تطبيق المنظومة علي الإني حجم دعم السلع التموينية

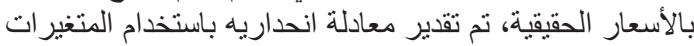

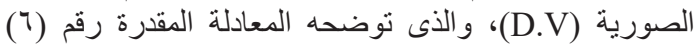
(جدول r)، حيث ينضح من معادلة الانحدار المقدرة ثبوت الإنة

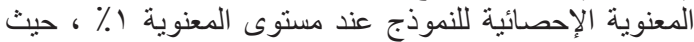

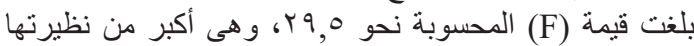

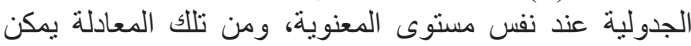
اشتقاق معادلات نوضح أنثر تطبيق المنظومة التالية:-

$\mathrm{Y} 0=2939$

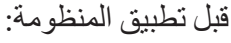

$\mathrm{Y} 1=9211$

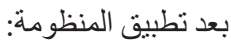

ويتضح من المعادلة المقدرة ارتفاع حجم الدعم بالأسعار

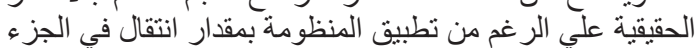

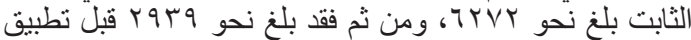

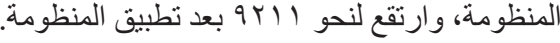

ومما سبق يتضح أن مقدار الانتقال في الجزء الثابت كان كان في

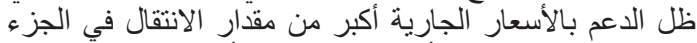

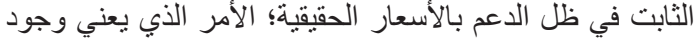
ارتفاع كبير في معدلات التضخم. 
في ظل الدعم بالأسعار الحقيقية:

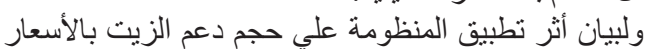

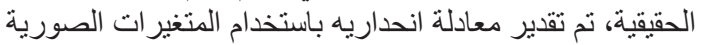
(P.V)

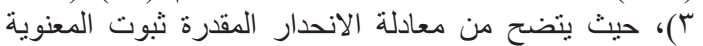

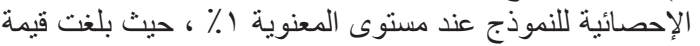

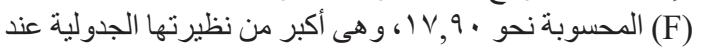

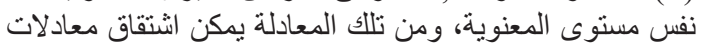
توضح أثر تطبيق المنظومة التالية:-

$\mathrm{Y} 0=1501$

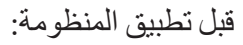

$\mathrm{Y} 1=4188$

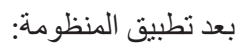

ويتضح من المعادلة المقدرة ارتفاع حجم الدعم بالأسعار

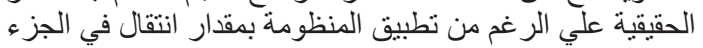

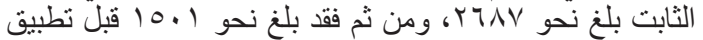
المنظومة، وارتقع لنحو 1 1 إك بعد تطبيق المنظومة.

ومما سبق يتضح أن مقدار الانتقال في الجزء الثابت كان في في الأني

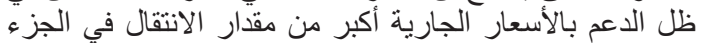

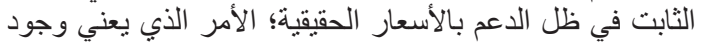
ارتفاع كبير في معدلات التضخم.

V-أثر تطبيق منظومة البطاقات الالكترونية علي الدعم الارز

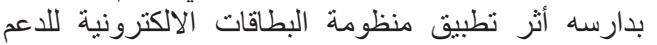

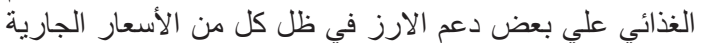

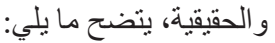

في ظل الدعم بالأسعار الجارية:

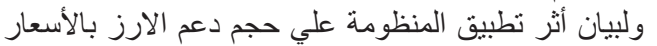

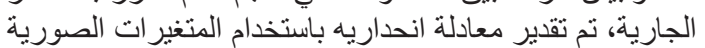
(P.V)

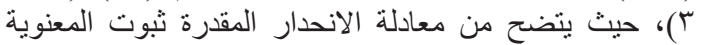

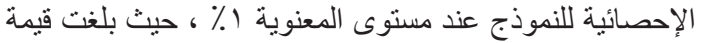

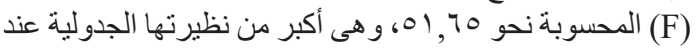

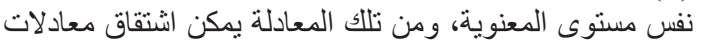
توضح أثر تطبيق المنظومة التالية:-

$\mathrm{Y} 0=612$ قبل تطبيق المنظومة:

$\mathrm{Y} 1=2315$

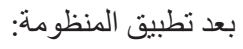

ويتضح من المعادلة المقدرة ارتفاع حجم الدعم بالأسعار

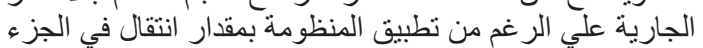

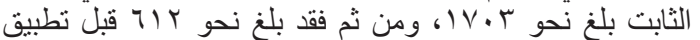

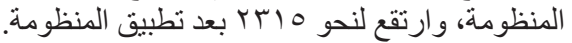

في ظل الدعم بالأسعار الحقيقية

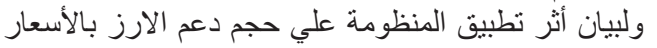

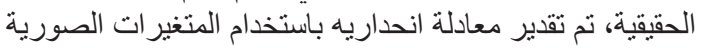
(P.V)

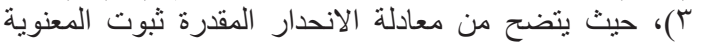

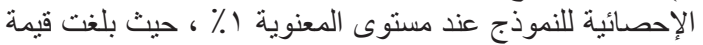

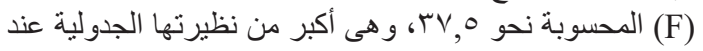

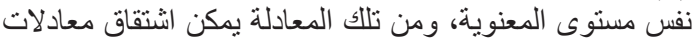
توضح أثر تطبيق المنظومة النالية:-

$\mathrm{Y} 0=444$

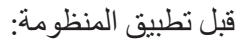

$\mathrm{Y} 1=1328$

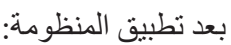

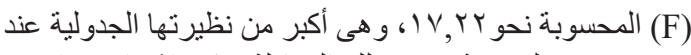

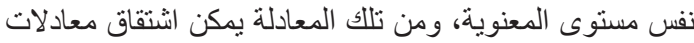
توضح أثر تطبيق المنظومة التالية:-

$\mathrm{Y} 0=1354$

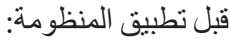

$\mathrm{Y} 1=4537$

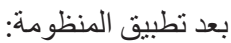

ويتضح من المعادلة المقدرة ارتفاع حجم الدعم بالأسعار

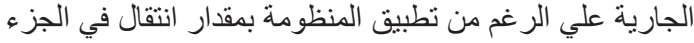

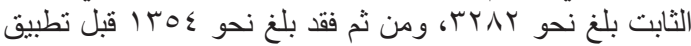

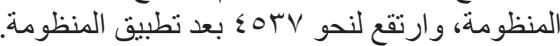

في ظل الدعم بالأسعار الحقيقية: ولبيان أثر تطبيق المنظومة علي حجم دعمة الأنمة السكر بالأسعار

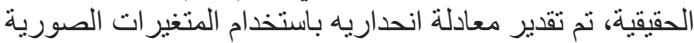

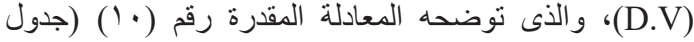

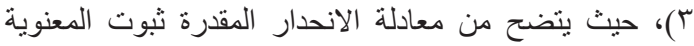

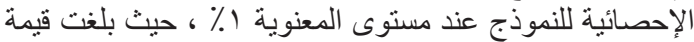

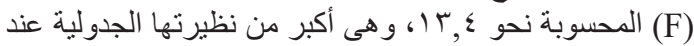
نفس مستوى المعنوية، ومن تلاك المعادلة المكادلة بمكن اشتقاق معادلات توضح أثر تطبيق المنظومة التالية:-

$\mathrm{Y} 0=994$ قبل تطبيق المنظومة:

$\mathrm{Y} 1=2654$

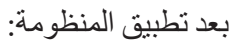

ويتضح من المعادلة المقدرة ارتفاع حجم الاعم بالأسعار

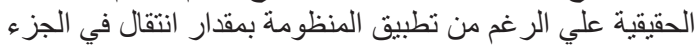

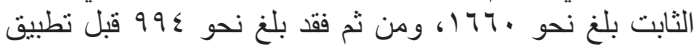
المنظومة، وارتقع لنحو ك70 ب بعد تطبيق المنظومة.

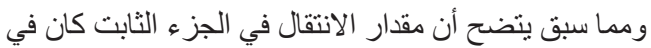

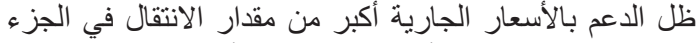
الثابت في ظل الدعم بالأسعار الحقيقية؛ الأمر الذي يعني الأني في وجود ارتفاع كبير في معدلات التضخم.

7ـأثر تطبيق منظومة البطاقات الالكترونية علي دعم الزيت

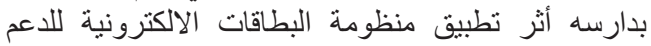
الغذائي علي بعض دارت دعم الزيت في ظل كل من الأسعار الجارية

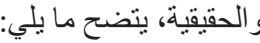

في ظل الدعم بالأسعار الجارية: ولبيان أثر تطبيث المنظومة علئ علي حجم دعم الزيت باريت بالأسعار

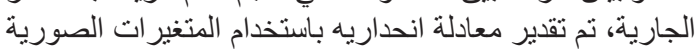
(D.V)

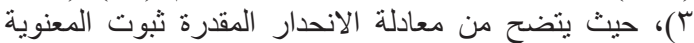

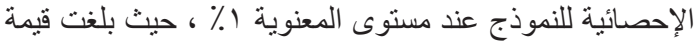

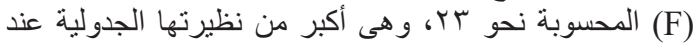

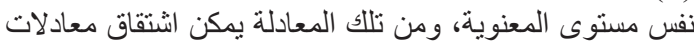
توضح أثر تطبيق المنظومة التالية:-

$\mathrm{Y} 0=2054$

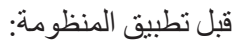
$Y 1=7294$

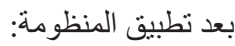

ويتضح من المعادلة المقدرة ارتفاع حجم الدعم بالأسعار

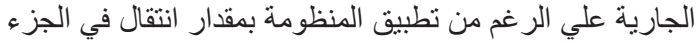

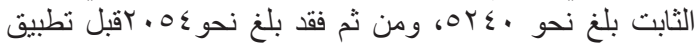

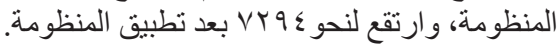

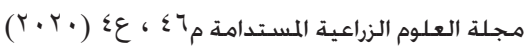




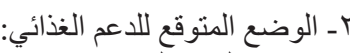

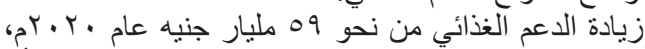

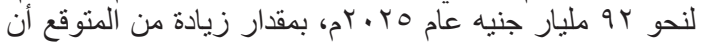

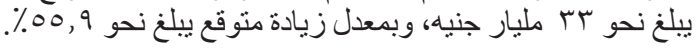

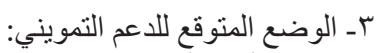

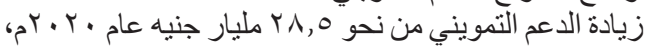

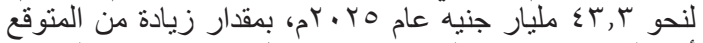

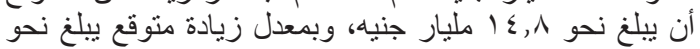
$\% 01,9$

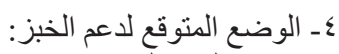

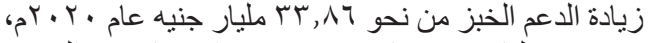

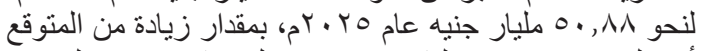

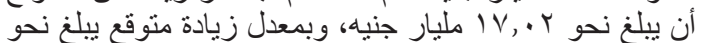
$\%$, r r

\section{التوصبات}

ا - زيادة الدعم الموجه للغذاء و السلع التموينية ور غيف الخبزحيث

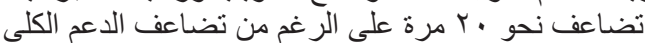

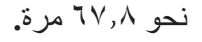

r- يستوجب تصحيح مسار الاعم ووصول الدعم للفئات الأكثر

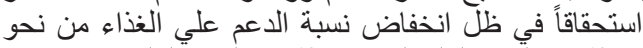
ب7\% من الدعم الكلي لنحو 9 1\% من الدعم الكلي .

$$
\text { rـ التوسع فى زر اعة محصول القمح }
$$

ع- زيادة نسبة الاعم الغذائى من الدعم الكلى وزيادة نصبي

$$
\text { محدود الاخل العل }
$$

هـ تقليل الدعم الكلى من الموازنة العامة عن طريق تقليل عدد
ويتضح من المعادلة المقدرة ارتفاع حجم الاعم بالأسعار

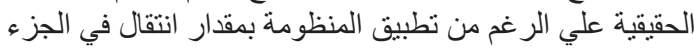

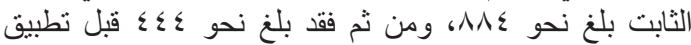

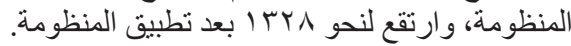

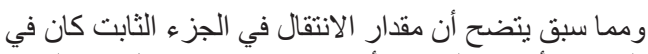

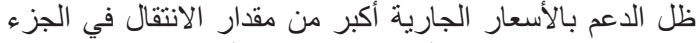
الثابت في ظل الدعم بالأسعار الحقيقية؛ الأمر الذي يعني الأني في وجود ارتفاع كبير في معدلات التضخم.

رابعاً: تطور الوضع المستقبلي لسياسات الدعم الغذائي في مصر

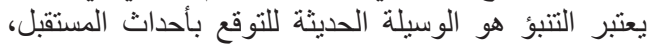

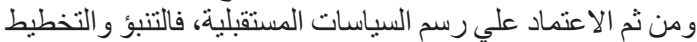

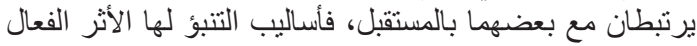

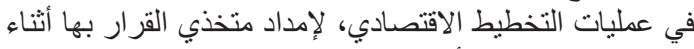

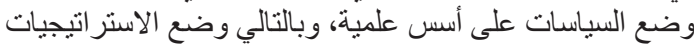

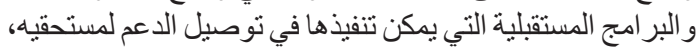

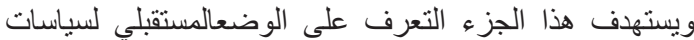

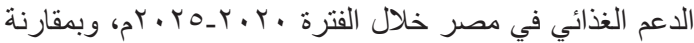

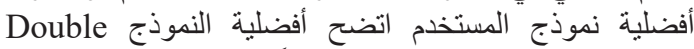
Exponential Model

\begin{tabular}{|c|c|c|c|c|c|c|c|c|}
\hline \multirow[b]{2}{*}{$\begin{array}{c}\text { Double } \\
\text { Exponential } \\
\text { Model }\end{array}$} & \multirow[b]{2}{*}{$\begin{array}{c}\text { Exponential } \\
\text { Model }\end{array}$} & \multicolumn{2}{|c|}{ الدعم التمويني } & \multicolumn{2}{|c|}{ الاعم الغذائي } & \multicolumn{2}{|c|}{ الدعم الكلي } & \multirow{2}{*}{ السنوات } \\
\hline & & $\begin{array}{c}\text { Double } \\
\text { Exponential } \\
\text { Model }\end{array}$ & $\begin{array}{c}\text { Exponential } \\
\text { Model }\end{array}$ & $\begin{array}{c}\text { Double } \\
\text { Exponential } \\
\text { Model }\end{array}$ & $\begin{array}{c}\text { Exponential } \\
\text { Model }\end{array}$ & $\begin{array}{c}\text { Double } \\
\text { Exponential } \\
\text { Model }\end{array}$ & $\begin{array}{c}\text { Exponential } \\
\text { Model }\end{array}$ & \\
\hline rr,人t & $\leq 9, \cdot 1$ & $r \wedge, 0$ & $r, 0$ & $09, r$ & $\lambda r, v$ & $r \varepsilon \varepsilon, r$ & $A r \leqslant, \varepsilon$. & $r \cdot r$. \\
\hline TV,Y & ov, 17 & T), 0 & $r q, 1$ & 70,1 & $9 \vee, 1$ & TVY,A & 1.or,or & $r \cdot r_{1}$ \\
\hline$\varepsilon \cdot, T V$ & 77,09 & $r \varepsilon, \varepsilon$ & $\varepsilon \vee, \cdot$ & $V Y, T$ & $11 \leq, 1$ & $\varepsilon \cdot 1, r$ & $I r \leqslant \tau, r r$ & r. r T \\
\hline $0 \cdot, \wedge \wedge$ & $1 \cdot 0, r \leq$ & $\varepsilon r, r$ & $\wedge 1,9$ & $9 r, \cdot$ & $110,$. & $\varepsilon \wedge 7,9$ & $r \wedge \cdot 9, \wedge$ & r. ro \\
\hline$\varepsilon \cdot, 7 v$ & $79, V T$ & $\Gamma \varepsilon, \varepsilon$ & $0 ., r$ & $V T, r$ & $\mid r \cdot, 1$ & $\varepsilon \cdot 1, r$ & $101 \leq$. & المنوسط \\
\hline Yr, IT & $r \cdot, \vee q q$ & IV,V & 17,9 & IV, & 17,19 & $\varepsilon \wedge, 1 \wedge$ & $\leq 1, \leqslant V$ & MAPE: \\
\hline$r, \varepsilon \tau$ & $r, 01$ & 1,11 & $\cdot, \wedge \wedge$ & $r, r \cdot$ & $r, r_{1}$ & $1 \wedge, \cdot 1$ & $\varepsilon r, q T$ & MAD: \\
\hline $19, \Gamma$. & $M, V \varepsilon$ & $r, \cdot r$ & $1, \pi$ & $r_{0, V} \varepsilon$ & $r r, \lambda)$ & $799, r)$ & EOr 1,7$\}$ & MSD: \\
\hline$\cdot, \cdot v$ & -- & $\cdot 9$. & -- & $\cdot, \cdot \varepsilon$ & -- & $\cdot, .0$ & -- & Alpha \\
\hline
\end{tabular}
المستخدم في التنبؤ، حيث يتضح من بيانات جدول (ع) )، ما يلى:

$$
\text { ا ـ الوضع المتوقع للاعم الكلي: }
$$

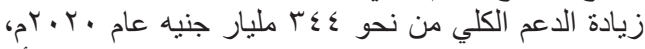

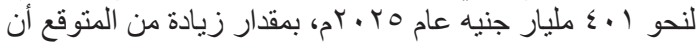

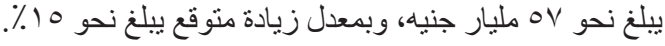

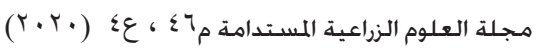


Youssef MH (2008). Role of Food Subsides on Poverty Alleviation in Egypt,The American University in Cairo, School of Business, Economics \& Communication, pp: 1-17.

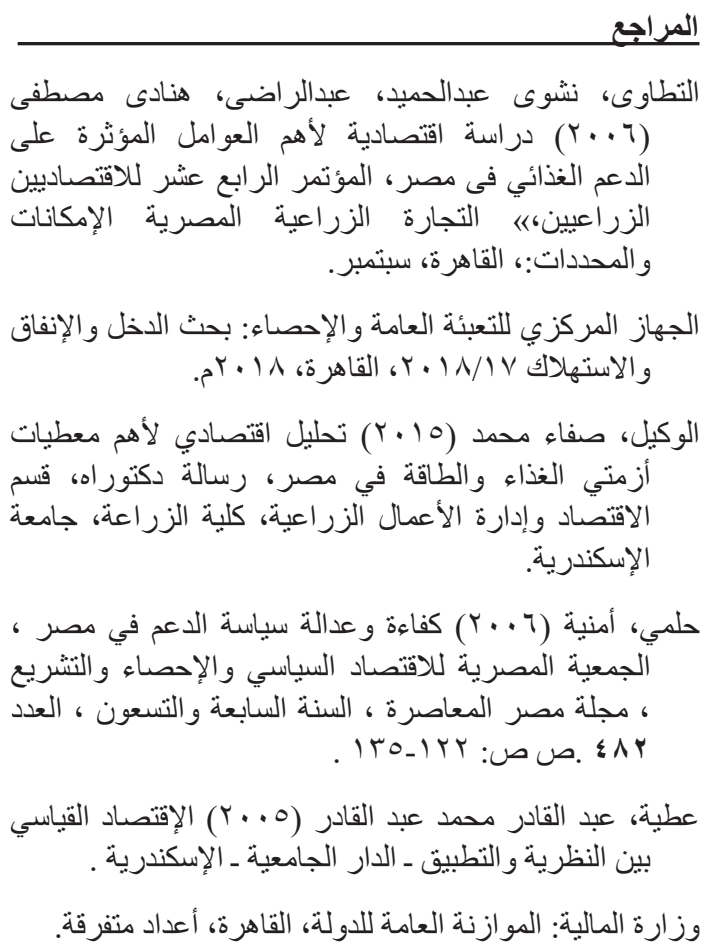

\title{
The Effect of Applying Digital Transformation System on the Support of Some Indicators Support Food
}

\author{
Mahmoud M. Fawaz ${ }^{1}$, MahamedF. Elsafty ${ }^{1}$, Elsayed M. Atallah ${ }^{2}$ and Khald EIBohy ${ }^{1}$ \\ ${ }^{1}$ Agricultural Economic Dept., Faculty of Agriculture, Kafrelsheikh University, \\ ${ }^{2}$ Department of Agricultural Economics, Faculty of Agriculture, Damietta Uni. \\ Damietta, Egypt.
}

$\mathbf{T}$

HE RESEARCH paper aims to know the targeted current and future status of food support and the impact of the application of the electronic card system for food support. Qualitative and quantitative methods were utilized to achieve the study purpose, as well as exponential function to estimate the growth rates, simple andlinear regression, Dummy variable and forecasting model, secondary data collected from CAPMS.The main results of the study included that,there is an increasing cash support trend towards food support,ration goods and bread support about $160 \%, 18 \%, 15 \%$ respectively during the period $2000-2019$, but $13 \%, 16 \%$, $11 \%$ in real support respectively during this period. The change rate of $1 \%$ total cash support will change the amount support of food by 0.208 unit, and change in the amount of cash support unit for the bread support will change the support food by 1.042 unit. It is expected to increase food subsidies an bread by about 22\%, 50\% 2025 respectively. In addition to subsidies for food, commodities and bread support has doubled about 20 times, despite the total support doubling about 67.8 times, this may necessary correcting the support path and reaching the support for the best. because decreasing percentage of food support from about $63 \%$ of the total support to about $19 \%$ of the total support during the period.

Key words: Food subsidies, food subsidies, digital homes, digital support, dummy variables, future prediction.

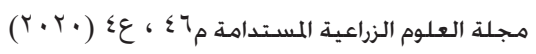

